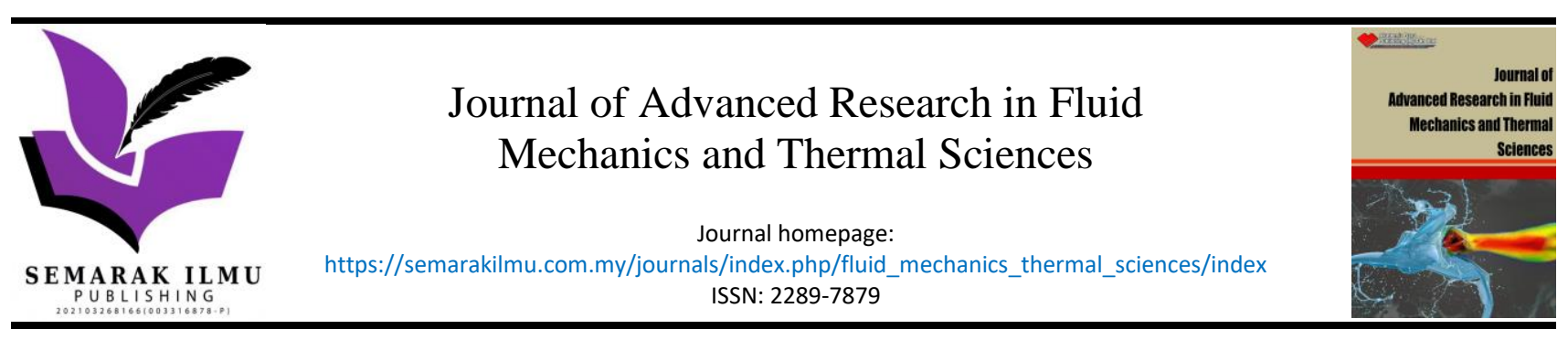

\title{
Peng-Robinson Cubic Equation of State Based on Key Group Contribution and Calculation of Nitrogen Gas Solubility in MMA Dimer
}

\author{
Abdul Aleem Seeni Mohamed ${ }^{1}$, Zi Ern Chong ${ }^{1}$, Andrea Jia Xin Lai ${ }^{1}$, Tomoya Tsuji ${ }^{1,}{ }^{*}$, Wen Chun \\ Siaw $^{1}$, Lian See Tan ${ }^{1}$, Ragunath Bharath ${ }^{2}$, Taka-aki Hoshina ${ }^{3}$ \\ Malaysia-Japan International Institute of Technology, Universiti Teknologi Malaysia, 54100 Kuala Lumpur, Malaysia \\ Innovative Fluid Process Sdn. Bhd. 40460 Shah Alam, Malaysia \\ College of Industrial Technology, Nihon University, 275-8575 Narashino, Japan
}

ARTICLE INFO ABSTRACT

\section{Article history:}

Received 29 June 2021

Received in revised form 14 August 2021

Accepted 17 August 2021

Available online 11 October 2021

\section{Keywords:}

Gas solubility; vinyl monomer; group contribution; Peng-Robinson equation of state; scaling
Previously authors have reported facts that nitrogen $\left(\mathrm{N}_{2}\right)$ and oxygen solubilities in styrene is the same as those in benzene and divinylbenzene at $303 \mathrm{~K}$. Though the three compounds have an atomic composition, $(\mathrm{CH})_{n}(n=6,8$ and 10), the gas solubilities are thought to depend on the number of aromatic carbons in the solution. Then, authors named it 'a key group in solubility'. In this research, the key group was investigated for $\mathrm{N}_{2}$ solubility in methyl methacrylate (MMA) and its dimer, ethylene glycol dimethacrylate (EGDMA). Therefore, the calculations were carried out by Peng-Robinson (PR) equation of state based on group contribution methods. The experimental data employed were those of Lai et al., where $\mathrm{N}_{2}$ solubility are reported in MMA at $303 \mathrm{~K}$. The $\mathrm{N}_{2}$ solubility in EGDMA was assumed to be double of that in MMA at $303 \mathrm{~K}$, because EGDMA has two MMA units in the molecule. Two types of group contribution methods were proposed to calculate $\mathrm{N}_{2}$ solubility in EGDMA. One was for the critical temperature and pressure proposed by Joback and Reid. Using these properties, the attractive and excluded volume parameters in PR equation were evaluated for EGDMA. Other was similar to a method proposed by Orbey and Sandler. The excluded volume parameter in PR equation can be evaluated from those of MMA by multiplying the number of repeating units, and the attractive by multiplying the squared number. Instead of the method, the powers were proposed to be $3 / 4$ and $3 / 2$ for the excluded volume and attractive perimeters, respectively. The powers were come from a scaling theory by de Gennes. The binary parameter for $\mathrm{N}_{2}-$ EGDMA was also set to $k_{12}=0.224$, which was the same as that for $\mathrm{N}_{2}$ -MMA. The calculated $\mathrm{N}_{2}$ solubility in EGDMA was far smaller than the hypothetical $\mathrm{N}_{2}$ solubility in EGDMA at $303 \mathrm{~K}$. Otherwise, to reproduce the hypothetical $\mathrm{N}_{2}$ solubility, a quite different value, $k_{12}=-0.044$, was necessary for the method by Joback and Reid. The results suggested that a key group for gas solubility will not be accepted in MMA.

\footnotetext{
* Corresponding author. E-mail address: t.tsuji@utm.my
} 


\section{Introduction}

Free radical polymerization is a common method for synthesizing polymers from vinyl monomers. Figure 1 shows the reaction scheme of free radical polymerization. It is composed of some elemental reactions [1,2], and divided into three steps, that is, initiation, propagation, and termination. If oxygen $\left(\mathrm{O}_{2}\right)$ is dissolved in the solution, propagation will be affected with the $n$-mer free radical, $I \mathrm{M}_{n}$ - [3-6] that will be converted to peroxide radical, $\mathrm{IM}_{\mathrm{n}}-\mathrm{O}-\mathrm{O} \cdot$, such that the reaction rate will be far larger than that in the absence of oxygen for which formation of the peroxide radical is slow. Therefore, usual propagation will not occur until oxygen dissolved in the solution is depleted and converted to peroxide radical. Thus, presence of oxygen molecules is well known to act as an inhibitor in radical polymerizations. To avoid oxygen inhibition, the monomer solution is saturated with nitrogen $\left(\mathrm{N}_{2}\right)$ or argon (Ar), which is a procedure often used in polymerizations carried out in the laboratory.

$$
\begin{aligned}
& \text { Initiation } \quad I_{2} \rightarrow 2 I \bullet \\
& \text { I• }+M \rightarrow I M \bullet \\
& I \cdot+\mathrm{O}_{2} \rightarrow I-O-O \cdot \text { (fast) } \\
& \text { Propagation } \quad I M_{n-1} \bullet+O_{2} \rightarrow I M_{n-1}-O-O \bullet \text { (fast) } \\
& I M_{n-1} \cdot+M \rightarrow I M_{n} \cdot \\
& I M_{n-1}-O-O \bullet+M \rightarrow I M_{n-1}-O-O-M \cdot \text { (slow) } \\
& I M_{n} \cdot \rightarrow \text { deactivated products } \\
& \text { Termination } \\
& I M_{n-1}-O-O \cdot+I M_{n-1}-O-O \cdot \rightarrow \\
& I M_{n-1}-O-O \cdot+I M_{n} \cdot \rightarrow \\
& I M_{n} \cdot+I M_{n} \cdot \rightarrow
\end{aligned}
$$

Fig. 1. Reaction scheme of radical polymerization of vinyl monomer and formation of peroxide by oxygen dissolved in solution; $I_{2}$ : initiator; $M$ : vinyl monomer

Styrene and methyl methacrylate (MMA) are the most popular vinyl monomers, and the bulk and the solution polymerization are widely employed in industry. For the design of the polymerization process, gas solubility data are necessary. In the previous research, the authors have reported $\mathrm{N}_{2}$ and $\mathrm{O}_{2}$ solubility in benzene, styrene and divinyl benzene at (293-303) $\mathrm{K}$ [7].

Figure 2 shows the molecular structure of benzene, styrene, and divinylbenzene. Benzene, styrene, and divinylbenzene correspond to the solvent, the monomer, and the cross linker with the same compositional formula $(\mathrm{CH})_{n}(n=6,8,10)$. If the solubility depends on the number of $(\mathrm{CH})$ groups in the solution, the gas solubility would be evaluated in the various solutions containing not only benzene, styrene, and divinylbenzene but polystyrene. 
Figure 3 provides a comparison of nitrogen and oxygen solubilities in benzene, styrene and divinylbenzene at $313 \mathrm{~K}$. Linear dependence in pressure was also observed for $\mathrm{N}_{2}$ and $\mathrm{O}_{2}$ solubilities in the three compounds, and it followed Henry's law at least up to $4 \mathrm{MPa}$. Surprisingly, the $\mathrm{N}_{2}$ solubility in benzene was almost the same as that in styrene and divinylbenzene with similar trends also being observed for oxygen. Before the measurements, it was expected that the gas solubility in $(\mathrm{CH})$ unit might be the same and that the correlation, using a group contribution method, could be available. However, the experimental data were found to depend mainly on the number of aromatic rings in the molecule. Therefore, the authors named the aromatic ring as a 'key group structure' in gas solubility. Successively, $\mathrm{N}_{2}$ solubilities in MMA have been also reported at (293-313) K in the previous research [8]. Then, a linear dependence in pressure that followed Henry's law was also observed for $\mathrm{N}_{2}$ and $\mathrm{O}_{2}$ solubilities in MMA. Therefore, in this research, the authors investigated whether a key group structure is existing in MMA by using a cubic equation of state, Peng-Robinson (PR) [9]. Ethylene glycol dimethylacrylate (EGDMA) was selected as a dimer of MMA. The molecular structures of MMA and EGDMA are shown in Figure 2. EGDMA is composed of two MMA units. If a key group structure is in MMA molecule, gas solubility in EGDMA were expected to be twice that in MMA.

Gas solubility, vapor-liquid equilibria (VLE) and the related applications have been intensively reported for carbon dioxide $\left(\mathrm{CO}_{2}\right)$ to apply to new technologies [10-15]. However, there are not so many researches of solubility and VLE for $\mathrm{CO}_{2}$ in MMA or EGDMA. Lora and McHugh [16] and Uzun et al., [17] have reported VLE for $\mathrm{CO}_{2}-\mathrm{MMA}$, and Zwolak et al., [18] have also reported $\mathrm{CO}_{2}$ solubility in MMA. Kim et al., [19] and Cho et al., [20] reported $\mathrm{CO}_{2}$ solubility in EGDMA. However, the available data, for $\mathrm{N}_{2}$ and $\mathrm{O}_{2}$ solubility in MMA, are just our previous research [8]. For $\mathrm{N}_{2}$ and $\mathrm{O}_{2}$ solubility in EGDMA, there is no available data in the literature.

In this research, two group contribution methods were proposed for EGDMA to estimate the parameters in PR equation. The calculations, using the methods, were compared with hypothetical $\mathrm{N}_{2}$ solubility data in EGDMA at $313.18 \mathrm{~K}$.

(a)<smiles>c1ccccc1</smiles>

(e)

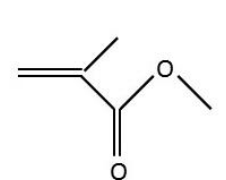

(b)<smiles>C=Cc1ccccc1</smiles>

(c)

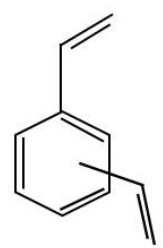

(f)

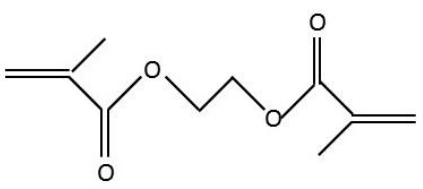

Fig. 2. Chemical structure of (a) benzene, $\mathrm{C}_{6} \mathrm{H}_{6}$, (b) styrene, $\mathrm{C}_{8} \mathrm{H}_{8}$, (c) Divinylbenzene, $\mathrm{C}_{10} \mathrm{H}_{10}$, (d) MMA, $\mathrm{C}_{5} \mathrm{H}_{8} \mathrm{O}_{2}$ and (e) EGDMA, $\left(\mathrm{C}_{5} \mathrm{H}_{7} \mathrm{O}_{2}\right)_{2}$ 


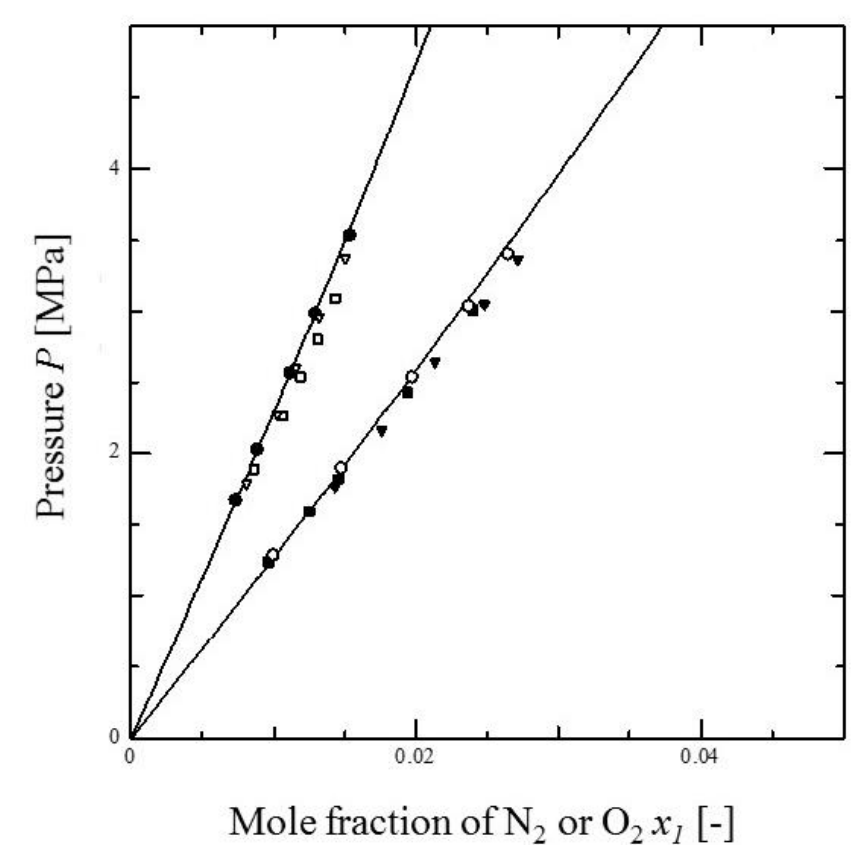

Fig. 3. Comparison of $\mathrm{N}_{2}$ and $\mathrm{O}_{2}$ solubilities in benzene, styrene, and divinylbenzene around $313 \mathrm{~K}$ [7] ; ( $\square): \mathrm{N}_{2}$ in benzene at $313.24 \mathrm{~K} ;(\bullet): \mathrm{N}_{2}$ in styrene at $313.30 \mathrm{~K} ;(\triangle): \mathrm{N}_{2}$ in divinylbenzne at $313.22 \mathrm{~K}$; (a): $\mathrm{O}_{2}$ in benzene at $313.23 \mathrm{~K}$; (O): $\mathrm{O}_{2}$ in styrene at $313.19 \mathrm{~K} ;(\boldsymbol{\Delta}): \mathrm{O}_{2}$ in divinylbenzene $313.24 \mathrm{~K}$

\section{Methodology}

\subsection{PR Equation of State}

PR equation of state [9] have been widely used in process simulators not only for industry but also for research and education, and it is given by

$P=\frac{R T}{v-b}-\frac{a}{v^{2}+2 b v-b^{2}}$

where $a$ and $b$ are attractive and excluded volume parameters of a pure compound. These are evaluated by applying corresponding state theory as follows

$$
\begin{aligned}
& a=0.45724 \frac{R^{2} T_{c}^{2}}{P_{c}}\left[1+\kappa\left\{1-\left(\frac{T}{T_{c}}\right)^{1 / 2}\right\}\right]^{2} \\
& b=0.07780 \frac{R T_{c}}{P_{c}} \\
& \kappa=0.37464+1.54226 \omega-0.26992 \omega^{2}
\end{aligned}
$$

where $T_{c}$ and $P_{c}$ are the critical temperature and pressure of pure compound. $\omega$ is acentric factor, which is obtained from temperature dependence of saturated vapor pressure [21] 
$\omega=-\left.\log _{10} P^{s}\right|_{T / T_{c}=0.7}-1.000$

Stryjek and Vera have proposed a modified version of PR (PRSV) equation, and improved the reliability for saturated vapor pressure [22]. Though PRSV equation has the same function form as that of PR equation, the estimation of $a$ and $b$ is slightly different from that of PR equation

$a=0.457235 \frac{R^{2} T_{c}^{2}}{P_{c}}\left[1+\kappa\left\{1-\left(\frac{T}{T_{c}}\right)^{1 / 2}\right\}\right]^{2}$

$b=0.077796 \frac{R T_{c}}{P_{c}}$

$\kappa=\kappa_{0}+\kappa_{1}\left[1+\left(\frac{T}{T_{c}}\right)^{1 / 2}\right]\left[0.7-\frac{T}{T_{c}}\right]$

$\kappa_{0}=0.378893+1.4897153 \omega-0.171318 \omega^{2}+0.0196554 \omega^{3}$

where $\kappa_{1}$ is a parameter, which is available in the literature [22]. Concerning gas solubility in this research, the parameter, $\kappa_{1}$, is provided just for $\mathrm{N}_{2}, \mathrm{O}_{2}$, and benzene. So, the parameters, $a$ and $b$, are estimated from the three properties, $T_{c}, P_{c}$ and $\omega$ as shown in Eqs.(2)-(4). However, there is no available data of $T_{c}, P_{c}$ and $\omega$ for EGDMA.

\subsection{Group Contribution Method}

To estimate the two parameters, $a$ and $b$, in PR equation for EGDMA, two group contribution methods were employed in this research. One was for the three properties, $T_{c}, P_{c}$ and $\omega$. The other was a direct estimation of $a$ and $b$ from those of the repeating unit, MMA. Figure 4 shows the groups in EGDMA based on the two group contribution methods. $T_{c}, P_{c}$ and $\omega$ were evaluated by a group contribution method proposed by Joback and Reid [23].

(a)

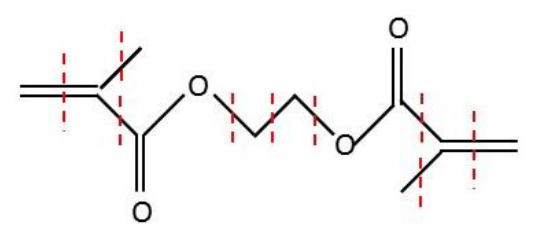

(b)

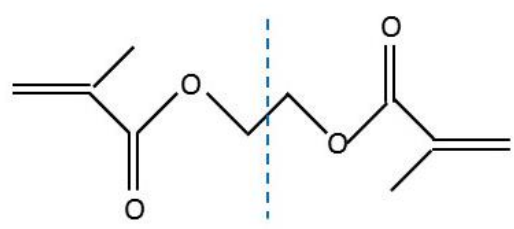

Fig.4. Group in EGDMA; (a) For Tc and Pc (Joback and Reid [23];

(b) for a and b (Orbay and Sandler [26])

According to the group contribution method, a molecule is divided into some functional groups, and $T_{c}$ and $P_{c}$ can be estimated as follows 


$$
\begin{aligned}
& T_{c}=\frac{T_{b}}{0.584+0.965 \sum \Delta_{T}-\left(\sum \Delta_{T}\right)^{2}} \\
& P_{c}=\frac{1}{\left(0.113+0.0032 N_{A}-\sum \Delta_{P}\right)^{2}}
\end{aligned}
$$

where $\Delta_{T}$ and $\Delta_{P}$ are group parameters for critical temperature and pressure, respectively, and they are available in the literature [23]. $T_{b}$ is normal boiling point, and $N_{A}$ is the number of atoms in a molecule. For saturated vapor pressure, the following function was assumed from normal boiling point to critical point.

$$
\log _{10} P^{s}=A+\frac{B}{T}
$$

where $A$ and $B$ are constants. Applying Eq. (5), acentric factor, $\omega$, is obtained as follows $[21,24,25]$

$$
\omega=\frac{1-0.7}{0.7} \times \frac{T_{b} / T_{c}}{1-\left(T_{b} / T_{c}\right)} \log _{10} \frac{P_{c}}{P_{a t m}}-1
$$

where $T_{b} / T_{c}$ was evaluated by Eq. (10), and $P_{a t m}$ is a standard atmospheric pressure, $101.325 \mathrm{kPa}$. Orbey and Sandler [26] have also proposed an estimation of $a$ and $b$ for polymer by using those for repeating unit, monomer. The $a$ and $b$ are given by

$$
\begin{aligned}
& a_{\text {polymer }}=\left(\frac{M_{w, \text { polymer }}}{M_{w, \text { monomer }}}\right)^{2} a_{\text {monomer }} \\
& b_{\text {polymer }}=\left(\frac{M_{w, \text { polymer }}}{M_{w, \text { monomer }}}\right) b_{\text {monomer }}
\end{aligned}
$$

where $M_{w, \text { polymer }}$ and $M_{w, \text { monomer }}$ are molecular weights of polymer and monomer, respectively. The method can be applied to EGDMA, and it is thought to be an another group contribution method. However, considering the physical meaning of the excluded volume parameter, $b$, an improvement seems to be necessary. Then, the details are described later.

\subsection{Mixing Rule}

For the estimation of $\mathrm{N}_{2}$ solubility, PR / PRSV equation will be extended to the binaries by using mixing rule for $a$ and $b$. Considering $\mathrm{N}_{2}$ and $\mathrm{O}_{2}$ solubilities shown in Figure 3, Henry's law is acceptable for the gas solubilities. Therefore, complex function forms will not be necessary in the mixing rule. So, conventional mixing rules, with simple function forms, were employed

$$
a=\sum_{i=1}^{2} \sum_{j=1}^{2} x_{i} x_{j}\left(1-k_{i j}\right)\left(a_{i} a_{j}\right)^{1 / 2}
$$




$$
b=\sum_{i=1}^{2} x_{i} b_{i}
$$

where $k_{i j}\left(=k_{i j}\right)$ is a binary interaction parameter. It is difficult to predict the values of $k_{i j}$. So, the values of $k_{i j}$ for $\mathrm{N}_{2}$ solubility in EGDMA were determined by the two methods. One was the same value as that in MMA. The other was newly determined by fitting with the hypothetical $\mathrm{N}_{2}$ solubility data in EGDMA. The methods were described later.

\section{Results and Discussion}

\section{1 $\mathrm{N}_{2}$ solubility in MMA and EGDMA}

Figure 5 shows $\mathrm{N}_{2}$ solubility in MMA at $313.18 \mathrm{~K}$, reported by Lai et al., [8]. The data were obtained by a synthetic type apparatus, and $\mathrm{O}_{2}$ and Ar solubilities were also reported. Linear dependence in pressure that followed Henry's law was observed, and the similar tendency was also reported for $\mathrm{O}_{2}$ and $\mathrm{Ar}$ solubilities in MMA. Otherwise, $\mathrm{N}_{2}$ solubility has not been reported yet in EGDMA. Then, $\mathrm{N}_{2}$ solubility in EGDMA were assumed to be twice that in MMA. The hypothetical $\mathrm{N}_{2}$ solubility in EGDMA was also shown in Figure 5.

\subsection{Correlation for $\mathrm{N}_{2}$ Solubility in $M M A$}

PR / PRSV equation showed good reproducibility not only for $\mathrm{N}_{2}$ and $\mathrm{O}_{2}$ solubility in styrene but also for $\mathrm{N}_{2}$ solubility in MMA [7,8]. Table 1 lists the parameters for $\mathrm{N}_{2}$ and MMA for PR / PRSV equation. As listed in Table 1, the critical properties of $\mathrm{N}_{2}$ and MMA were from Stryjek and Vera [16] and Lora and McHugh [10], respectively.

The binary interaction parameter, $k_{12}$, was fitted with the experimental data to minimize the following objective function, $O . F$.

$$
O . F .=\sum_{i}\left(x_{1, \text { cal }}-x_{1, \mathrm{exp}}\right)
$$

Table 2 lists the binary interaction parameters.

\section{Table 1}

Critical properties for MMA and EGDMA

\begin{tabular}{llllll}
\hline & Molecular weight & Critical temperature & Critical Pressure & Acentric factor & Parameter in PRSV eq. \\
& $M_{w} /-$ & $T_{c} / \mathrm{K}$ & $P_{c} / \mathrm{K}$ & $\omega /-$ & $\kappa_{1} /-$ \\
\hline Nitrogen & 28.013 & ${ }^{a} 126.200$ & ${ }^{a} 3.400$ & ${ }^{a} 0.03726$ & ${ }^{a} 0.01996$ \\
MMA & 100.117 & ${ }^{b} 563.95$ & ${ }^{b} 3.68$ & ${ }^{b} 0.317$ & \\
EGDMA & 198.22 & ${ }^{c} 692.0$ & ${ }^{c} 2.32$ & ${ }^{c} 0.679$ & \\
\hline
\end{tabular}

${ }^{a}$ Ref. [22]; ${ }^{b}$ Ref. [16]; ${ }^{c}$ Group contribution method by Joback and Reid [23]

Table 2

Binary interaction parameters in PR / PRSV equation

\begin{tabular}{ll}
\hline & Binary interaction parameter $k_{12}\left(=k_{21}\right) /-$ \\
\hline $\mathrm{N}_{2}(1)-$ MMA (2) & 0.224 \\
$\mathrm{~N}_{2}(1)-$ EGDMA (2) & ${ }^{a}-0.044$ \\
\hline${ }^{a_{\text {for }}}$ PR / PRSV equation using group contribution method by Joback and Reid [23] for EGDMA
\end{tabular}




\subsection{Prediction for $\mathrm{N}_{2}$ Solubility in EGDMA}

Table 3 lists the parameters in the group contribution method for $T_{c}$ and $P_{c}$, and Table 1 also lists the evaluated $T_{c}$ and $P_{c}$. Then, $N_{A}$ in Eq. (10), was set to be 28, and the normal boiling point, $T_{b}$, employed was that by Kim et al., [19]. Consequently the value of $T_{c}$ and $P_{c}$ was ensured the same as those of Kim et al., [19]. Figure 5 shows the prediction for $N_{2}$ solubility in EGDMA under the assumption of the same value of the binary interaction parameter as that for $\mathrm{N}_{2}-$ EGDMA. As shown in Figure 5, the prediction for $\mathrm{N}_{2}$ solubility in EGDMA was almost the same as that in MMA. Therefore, the predicted solubility was a half of the hypothetical $\mathrm{N}_{2}$ solubility in EGDMA. Figure 5 also shows the result using the binary interaction parameter fitted with the hypothetical $\mathrm{N}_{2}$ solubility in EGDMA. The value was listed in Table 2. The sign of the parameter was changed to be negative, so it means that the microscopic solution structure would be changed. Considering the similar structure in MMA and EGDMA, the phenomena will not to be accepted.

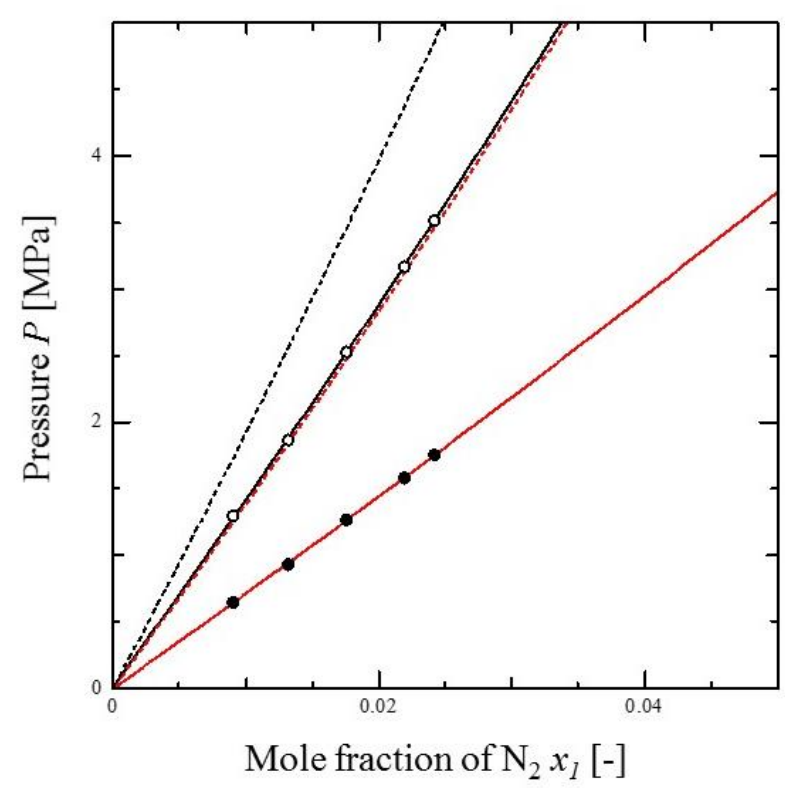

Fig. 5. Comparison of $\mathrm{N}_{2}$ solubilities in $M M A$ and EGDMA; (o) MMA at $313.18 \mathrm{~K}$; (•) EGDMA at $313.18 \mathrm{~K}$ (hypothetical); (— ) : PR / PRSV equation for MMA; (-------): PR /PRSV equation by Orbey and Sandler method with SAW model for EGDMA $\left(k_{12}=0.224\right)$; (------): PR /PRSV eq. by Joback and Reid method for EGDMA ( $\left.k_{12}=0.224\right)$; ( _ $)$ : PR / PRSV equation by Joback and Reid method for EGDMA ( $\left.k_{12}=-0.044\right)$

Table 3

Parameters for EGDMA in group contribution method by Joback and Reid [23]

\begin{tabular}{llll}
\hline Group & Number of group & \multicolumn{2}{l}{ Value of group parameter } \\
\cline { 3 - 4 } & & $\Delta_{T}$ & $\Delta$ \\
\hline$-\mathrm{CH}_{3}$ & 2 & 0.0141 & -0.0012 \\
$-\mathrm{CH}_{2}-$ & 2 & 0.0189 & 0.0000 \\
$=\mathrm{CH}_{2}$ & 2 & 0.0013 & -0.0028 \\
$=\mathrm{C}<$ & 2 & 0.0117 & 0.0011 \\
$-\mathrm{COO}-$ & 2 & 0.0481 & 0.0005 \\
\hline
\end{tabular}


Prior to the calculation by group contribution method by Orbey and Sandler [26], Eq. (14) and (15) were considered again from a view point of physical meaning by using a scalling model of de Gennes [21]. The parameter, $b$, is an excluded volume parameter. If that of $n$-mer is proportional to the degreed of polymerization, it is converted to the rigid rod (RR) model as follows

$L=n l$

where $L$ and I correspond to end-to-end distance, and length of repeating unit. Considering the flexibility of molecule of repeating unit, the evaluation, $b=\left(M_{w, E G D M A} / M_{w, M M A}\right) b_{M M A}$ seems to be an overestimation. Otherwise, in random walk (RW) model, end-to-end distance, $L$, is mathematically given by

$L=n^{1 / 2} l$

Therefore, $b=\left(M_{w, E G D M A} / M_{w, M M A}\right)^{1 / 2} b_{M M A}$ can be derived. However, it seems to be an underestimation because the over lapping is not allowed in the configuration. Then, self-avoiding walk (SAW) model was employed in this research.

Figure 6 shows illustration of the three models [27]. In SAW model, the power for the number of repeating units will be smaller than that RR model, and larger than that of RW model. Consequently, the following relation was assumed as follows

$a_{E G D M A}=\left(\frac{M_{w, E G D M A}}{M_{w, M M A}}\right)^{3 / 2} a_{M M A}$

$b_{E G D M A}=\left(\frac{M_{w, E G D M A}}{M_{w, M M A}}\right)^{3 / 4} b_{M M A}$

where $M_{w, E G D M A}$ and $M_{w, M M A}$ are molecular weights of EGDMA and MMA, respectively.

Figure 5 shows the prediction for $\mathrm{N}_{2}$ solubility in EGDMA under the assumption of the same value of the binary interaction parameter as that for $N_{2}-$ EGDMA. As shown in Figure $5, N_{2}$ solubility predicted was far smaller than the hypothetical data. If the interaction parameter was fitted with the hypothetical data, the values will be smaller than $k_{12}=-0.044$. So, any prediction was not carried out in this research.

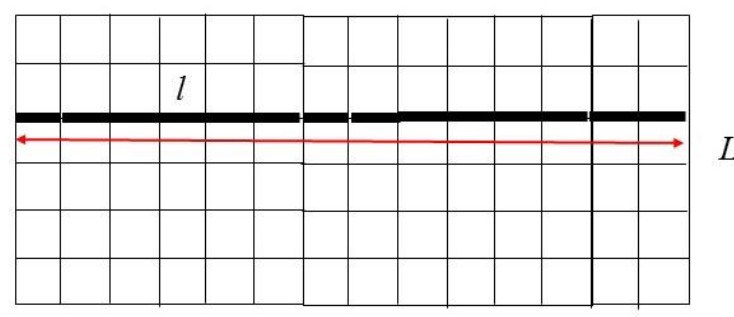

(a)

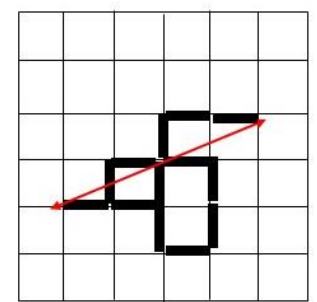

(b)

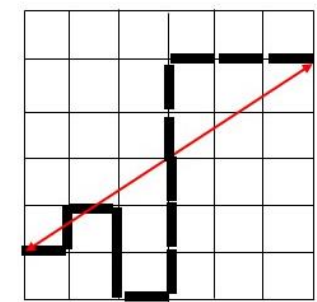

(c)

Fig. 6. Models of end to end distance in a molecule composed of some repeating units; (a) Ridged rod (RR); (b) Random walk (RD; (c) Self-avoiding walk (SAW) 


\section{Conclusions}

Two group contribution models were proposed for $\mathrm{N}_{2}$ solubility prediction in EGDMA, dimer of MMA. The model by Joback and Reid [17] showed the same $\mathrm{N}_{2}$ solubility as that in MMA by using a common binary interaction parameter, $k_{12}=0.224$. Considering the calculation results, a key group for gas solubility will not be accepted in MMA. The result was different from that in styrene. However, the data of EGDMA is hypothetical ones, so the actual experimental data of $\mathrm{N}_{2}$ solubility is required in EGDMA for further investigation of key group in gas solubility.

\section{Acknowledgement}

This work is funded by the Ministry of Higher Education under Fundamental Research Grant Scheme (FRGS/1/2018/TK02/UTM/01/6).

\section{References}

[1] Flory, Paul J. Principles of polymer chemistry. Cornell University Press, 1953.

[2] Reich, L., and S. S. Stivala. "Various types of polymer degradation." Elements of polymer degradation. McGraw Hill, New York (1971).

[3] Barnes, Carl E. "Mechanism of Vinyl Polymerization. I. Role of Oxygen1." Journal of the American Chemical Society 67, no. 2 (1945): 217-220. https://doi.org/10.1021/ja01218a023

[4] Kolthoff, I. M., and W. J. Dale. "The Mechanism of Emulsion Polymerizations. II. The Effect of Oxygen on the Emulsion Polymerization of Styrene1." Journal of the American Chemical Society 69, no. 2 (1947): 441-446. https://doi.org/10.1021/ja01194a072

[5] Bovey, F. A., and I. M. Kolthoff. "The Mechanism of Emulsion Polymerizations. III. Oxygen as a Comonomer in the Emulsion Polymerization of Styrene1." Journal of the American Chemical Society 69, no. 9 (1947): 2143-2153. https://doi.org/10.1021/ja01201a028

[6] McGinniss, V. D., T. Provder, C. Kuo, and A. Gallopo. "Polymerization of Methyl Methacrylate Photoinitiated by 4, 4'-Bis (N, N-diethylamino) benzophenone. 2. Oxygen Effects." Macromolecules 11, no. 2 (1978): 405-409. https://doi.org/10.1021/ma60062a023

[7] Tsuji, Tomoya, Kohei Ohya, Andrea Jia Xin Lai, Norhuda Binti Abdul Manaf, Taka-aki Hoshina, and Shigeo Oba. "Gas solubilities of nitrogen or oxygen in benzene, divinylbenzene, styrene and of an equimolar (N2: O2) mixture in styrene at (293-313) K." Fluid Phase Equilibria 492 (2019): 34-40. https://doi.org/10.1016/i.fluid.2019.03.016

[8] Lai, Andrea Jia Xin, Tomoya Tsuji, Lian See Tan, Ragunath Bharath, Taka-aki Hoshina, and Toshitaka Funazukuri. "Argon Gas Solubility in Styrene and Nitrogen, Oxygen and Argon Gas Solubilities in Methyl Methacrylate at (293 to 313) $\mathrm{K}$ and at Pressures up to 3.8 MPa." Journal of Solution Chemistry (2021): 1-19. https://doi.org/10.1007/s10953-021-01101-7

[9] Peng, D. Y., and D. B. Robinson. "Industrial Engineering Chemistry Fundamentals." A new two-constant equation of state 15 (1976): 59-64. https://doi.org/10.1021/i160057a011

[10] Zainuddin, Nur Ain Mohd, Farahhanis Tuah, and Mohd Azahar Mohd Ariff. "Effect of Pressure on Essential Oil Yield of Chromolaena Odorata Leaves Extract using Supercritical Fluid Carbon Dioxide." Journal of Advanced Research in Applied Sciences and Engineering Technology 17, no. 1 (2019): 29-35.

[11] Qamar, Rizwan Ahmed, Asim Mushtaq, Ahmed Ullah, and Zaeem Uddin Ali. "Aspen HYSYS Simulation of CO2 Capture for the Best Amine Solvent." Journal of Advanced Research in Fluid Mechanics and Thermal Sciences 68, no. 2 (2020): 124-144. https://doi.org/10.37934/arfmts.68.2.124144

[12] Hailegiorgis, Sintayehu Mekuria, Saleem Nawaz Khan, Nur Hanis H. Abdolah, Muhammad Ayoub, and Aklilu Tesfamichael. "Investigation of Carbon Dioxide Solubility in Aqueous Nmethyldiethanolamine (MDEA)-1-butyl-3methylimidazolium acetate ([bmim][Ac]) Hybrid Solvent." Journal of Advanced Research in Fluid Mechanics and Thermal Sciences 42, no. 1 (2018): 65-71. https://doi.org/10.1063/1.5005379

[13] Khan, Saleem Nawaz, Sintayehu Mekuria Hailegiorgis, Zakaria Man, and Azmi Mohd Shariff. "Solubility of CO2 in Piperazine (PZ) Activated Aqueous NMethyldiethanolamine (MDEA) Solvent under High Pressure." Journal of Advanced Research in Fluid Mechanics and Thermal Sciences 42, no. 1 (2018): 96-102.

[14] Rahman, Musfika, and Iskandar Dzulkarnain. "Response Surface Method for Modelling the Effect of CO2 in Brine/Waxy Oil Interfacial Tension during LSW-WAG Enhanced Oil Recovery." Journal of Advanced Research in Applied Sciences and Engineering Technology 22, no. 1 (2021): 54-68. 
[15] Rahman, Musfika, and Iskandar Dzulkarnain. "RSM for Modelling the CO2 Effect in the Interfacial Tension Between Brine and Waxy Dulang Crude Oil During LSW-WAG EOR." Journal of Advanced Research in Fluid Mechanics and Thermal Sciences 85, no. 2 (2021): 159-174. https://doi.org/10.37934/arfmts.85.2.159174

[16] Lora, Michele, and Mark A. McHugh. "Phase behavior and modeling of the poly (methyl methacrylate)-CO2-methyl methacrylate system." Fluid Phase Equilibria 157, no. 2 (1999): 285-297. https://doi.org/10.1016/S03783812(99)00043-6

[17] Lora, Michele, and Mark A. McHugh. "Phase behavior and modeling of the poly (methyl methacrylate)-CO2-methyl methacrylate system." Fluid Phase Equilibria 157, no. 2 (1999): 285-297. https://doi.org/10.1016/S03783812(99)00043-6

[18] Zwolak, Grzegorz, Liwan Lioe, and Frank P. Lucien. "Vapor- liquid equilibria of carbon dioxide+ methyl methacrylate at 308, 313, 323, and 333 K." Industrial \& engineering chemistry research 44, no. 4 (2005): 1021-1026. https://doi.org/10.1021/ie049823d

[19] Kim, Jong Ho, Byoung Kyu Kwak, Hyeon-Soo Park, Nam Gyu Kim, Kyunghee Choi, and Jongheop Yi. "A GIS-based national emission inventory of major VOCs and risk assessment modeling: Part I-methodology and spatial pattern of emissions." Korean journal of chemical engineering 27, no. 1 (2010): 129-138. https://doi.org/10.1007/s11814009-0307-3

[20] Cho, Dong Woo, Ju Ho Lee, Jungin Shin, Won Bae, Hwayong Kim, and Moon Sam Shin. "High-pressure phase behaviour measurement of ( $\mathrm{CO} 2+$ ethylene glycol dimethacrylate) and (CO2+ di-ethylene glycol dimethacrylate) binary mixture systems." The Journal of Chemical Thermodynamics 43, no. 11 (2011): 1666-1671. https://doi.org/10.1016/j.jct.2011.05.031

[21] Poling, Bruce E., John M. Prausnitz, and John P. O'connell. Properties of gases and liquids. McGraw-Hill Education, 2001.

[22] Stryjek, R., and J. H. Vera. "PRSV: An improved Peng-Robinson equation of state for pure compounds and mixtures." The canadian journal of chemical engineering 64, no. 2 (1986): 323-333. https://doi.org/10.1002/cjce.5450640224

[23] Joback, Kevin G., and Robert C. Reid. "Estimation of pure-component properties from groupcontributions." Chemical Engineering Communications 57, no. 1-6 (1987): $233-243$. https://doi.org/10.1080/00986448708960487

[24] Tsuji, Tomoya, Toshihiko Hiaki, and Masaru Hongo. "Vapor- Liquid Equilibria of the Three Binary Systems: Water+ Tetraethylene Glygol (TEG), Ethanol+ TEG, and 2-Propanol+ TEG." Industrial \& engineering chemistry research 37, no. 5 (1998): 1685-1691. https://doi.org/10.1021/ie9706469

[25] Tsuji, Tomoya, Ryoichi Shinozuka, Lian See Tan, Taka-aki Hoshina, Shigeo Oba, and Katsuto Otake. "SO 2 Solubility in Low Molecular Weight Polyethylene Glycol Dimethyl Ether and Correlation using Cubic Equation of State." Journal of Solution Chemistry 48, no. 7 (2019): 1035-1045. https://doi.org/10.1007/s10953-019-00873-3

[26] Orbey, Nese, and Stanley I. Sandler. "Vapor-liquid equilibrium of polymer solutions using a cubic equation of state." AlChE journal 40, no. 7 (1994): 1203-1209. https://doi.org/10.1002/aic.690400711

[27] De Gennes, Pierre-Gilles, and Pierre-Gilles Gennes. Scaling concepts in polymer physics. Cornell university press, 1979. 